\title{
BMJ Role of public and private funding Open in the rising caesarean section rate: a cohort study
}

\author{
Kristjana Einarsdóttir, ${ }^{1}$ Fatima Haggar, ${ }^{2}$ Gavin Pereira, ${ }^{1,3}$ Helen Leonard, ${ }^{1}$ \\ Nick de Klerk, ${ }^{1}$ Fiona J Stanley, ${ }^{1}$ Sarah Stock $^{4}$
}

To cite: Einarsdóttir K, Haggar F, Pereira G, et al. Role of public and private funding in the rising caesarean section rate: a cohort study. BMJ Open 2013;3:e002789.

doi:10.1136/bmjopen-2013002789

- Prepublication history for this paper are available online. To view these files please visit the journal online (http://dx.doi.org/10.1136/ bmjopen-2013-002789).

Received 25 February 2013 Revised 26 March 2013 Accepted 5 April 2013

This final article is available for use under the terms of the Creative Commons Attribution Non-Commercial 2.0 Licence; see http://bmjopen.bmj.com

For numbered affiliations see end of article.

Correspondence to Dr Kristjana Einarsdóttir; keinarsdottir@ichr.uwa.edu.au

\section{ABSTRACT}

Objective: The caesarean section rates have been rising in the developed world for over two decades. This study assessed the involvement of the public and private health sectors in this increase.

Design: Population-based, retrospective cohort study. Setting: Public and private hospitals in Western Australia.

Participants: Included in this study were 155646 births to nulliparous women during 1996-2008.

Main outcome measures: Caesarean section rates were calculated separately for four patient type groups defined according to mothers' funding source at the time of birth (public/private) and type of delivery hospital (public/private). The average annual per cent change (AAPC) for the caesarean section rates was calculated using joinpoint regression.

Results: Overall, there were 45903 caesarean sections performed (29\%) during the study period, 24803 in-labour and 21100 prelabour. Until 2005, the rate of caesarean deliveries increased most rapidly on average annually for private patients delivering in private hospitals $(\mathrm{AAPC}=6.5 \%$ ) compared with public patients in public hospitals (AAPC $=4.3 \%, p<0.0001$ ).

This increase could mostly be attributed to an increase in prelabour caesarean deliveries for this group of women and could not be explained by an increase in breech deliveries, placenta praevia or multiple pregnancies.

Conclusions: Our results indicate that an increase in the prelabour caesarean delivery rate for private patients in private hospitals has been driving the increase in the caesarean section rate for nulliparous women since 1996. Future research with more detailed information on indication for the prelabour caesarean section is needed to understand the reasons for these findings.

\section{INTRODUCTION}

The rising caesarean section rate in the developed world is of great concern. In the USA, rates of operative deliveries rose from $23 \%$ in 1991 to $32 \%$ in $2007^{1}$; in Canada, they increased from $18 \%$ in $1994-1995^{2}$ to

\section{ARTICLE SUMMARY}

Article focus

- Caesarean delivery rates in the developed world have been rising. Recent evidence from New South Wales, Australia published last year has indicated that differences between public and private hospitals influence caesarean delivery rates.

- However, results from a similar study published at the same time do not appear to corroborate this observation as the authors found no difference in the rising caesarean delivery rate according to the patient funding source.

- The objective of this study was to use data from Western Australia to investigate this issue by analysing both delivery hospital and funding source at the time of birth.

\section{Key messages}

- From 1996 to 2005, the rising caesarean delivery rate in nulliparous women could mostly be attributed to an increase in prelabour caesarean deliveries for private patients delivering in private hospitals.

- The rising prelabour caesarean delivery rate for this group of women could not be explained by an increase in breech deliveries, placenta praevia or multiple pregnancies.

- Future research with more detailed information on indication for prelabour caesarean section is needed to understand the reasons for these findings.

Strength and limitations of this study

- This study used routinely collected administrative hospital data collected at the time of birth for the entire population of Western Australia. Using these data therefore minimised limitations due to the sample size, selection bias or retrospective ascertainment of outcome measures.

- However, we were restricted in the detail of information available to us, as we did not have specific information on indications for caesarean section. Such information would have been useful to more accurately determine the reason for the rise in privately performed prelabour caesarean sections observed in this study. 
$26 \%$ in $2005-2006,{ }^{3}$ and in Australia, caesarean section rates rose from $18 \%$ in $1991^{4}$ to $31 \%$ in $2008,{ }^{5}$ thus already reaching a higher prevalence than the $25 \%$ reported for England in 2011-2012. ${ }^{6}$ While it is clear that adequate access to emergency operative delivery can save the life of both the mother and infant, ${ }^{78}$ high rates (particularly rates above $15 \%$ ) have not been shown to improve pregnancy outcomes, and may have a deleterious effect on future pregnancies. ${ }^{9-22}$ Reasons for the increase in caesarean section rates in the developed world are complex, and may include fear of litigation, ${ }^{23}$ maternal request, ${ }^{24}$ previous caesarean section ${ }^{25}$ and reduction in vaginal birth after a primary caesarean section. ${ }^{26}{ }^{27}$ However, the increased incidence of maternal or fetal risk factors does not appear to be a major factor. ${ }^{28-30}$

The healthcare system in Australia has similar features to the US and UK systems. Australian residents can give birth at no out-of-pocket cost in public hospitals via national health insurance (public patients), or choose to deliver as private patients at either private or public hospitals at their own expense or at a subsidised cost through private health insurance. ${ }^{31}{ }^{32}$ Antenatal care is provided by private obstetricians for private patients and by rostered midwives, residents, registrars and staff obstetricians for public patients. Recent evidence from New South Wales, Australia published last year indicated that the rise in the caesarean delivery rate has been higher in women delivering in private hospitals than public hospitals. ${ }^{33}$ A similar study published at the same time divided caesarean delivery rates during 1994-2009 by patient funding source only-not hospital type-and found similar increases in the caesarean section rates for private and public patients. ${ }^{34}$ The finding from the first study indicates that differences in delivery management between public and private hospitals influence caesarean delivery rates, but the latter result does not appear to corroborate this observation. The objective of this study was to use data from Western Australia to investigate this issue by analysing caesarean delivery rates in four patient groups stratified according to the type of delivery hospital (private/public) and funding source (private/ public) at the time of birth.

\section{METHODS}

Study data

This study used routinely collected administrative data from the Midwives Notification System held by the Western Australian Department of Health. The midwives data included births occurring on or after 20 weeks' gestation or infants born with a birth weight of at least $400 \mathrm{~g}$. It also included information on maternal characteristics, pregnancy complications, labour and delivery complications, and newborn characteristics for each of the births. The midwives data were linked with data from the Hospital Morbidity Data Collection in order to obtain information on the mother's hospital stay at the time of birth. This information included patient funding source and type of delivery hospital.
The collection of birth and hospital data is governed by legislation requiring all births as well as all hospital admissions to all hospitals in Western Australia to be registered. Both data systems regularly undergo stringent quality audits by the Western Australian Department of Health. Computerised probabilistic matching is used to link data relating to the same person from the two different datasets. Linking procedures are based on full name and address, date of birth and other identifiers and are estimated to be $99.89 \%$ accurate. ${ }^{35}$

\section{Study cohort}

Between 1 January 1996 and 31 December 2008, there were 343824 births in Western Australia. As a subsequent mode of delivery is strongly influenced by the prior mode of delivery, we restricted the analysis to nulliparous women (158 998 births). The study cohort thus included all hospital births to nulliparous mothers from 1 January 1996 to 31 December 2008 with information on funding source and hospital type ( $\mathrm{n}=155646,98 \%)$.

\section{Comparison groups}

Private patients were defined as those funded with private health insurance or those who were self-funded, whereas public patients included those insured under the Australian Health Care Agreements and Reciprocal Health Care Agreements. The cohort was further subdivided according to the hospital type of delivery. Hospital types coded in the hospital data as 'private metro' were defined as private and hospital types coded as 'tertiary', 'public metro', 'rural public/private' or 'Fremantle' were defined as public (all except three rural hospitals in Western Australia are public and both hospitals under the Fremantle Health Service are public).

In Western Australia, both public and private patients can choose to give birth in either public or private hospitals, but public patients were not able to give birth in private hospitals until 1996, when public patient facilities were established at a large private metropolitan hospital in Perth, Western Australia. ${ }^{36}$ Funding source (private/ public patient) and hospital type (private/public) were therefore categorised together into four groups of patients: public patients delivering in public hospitals, public patients in private hospitals, private patients in public hospitals and private patients in private hospitals.

Caesarean sections were categorised as prelabour or in labour, as recorded in the midwives data. Neonatal presentation was categorised as breech or vertex and multiple pregnancies included all multiples.

\section{Statistical analysis}

The average annual per cent change (AAPC) and 95\% CIs for the trend in caesarean delivery rate during 1996-2008 was calculated using the Joinpoint Regression Program V.3.4.3 (http://surveillance.cancer.gov/ joinpoint/). The joinpoint regression analysis was used to identify points at which statistically significant changes in temporal trend occurred and to calculate the average 
percentage change in caesarean delivery rate per year across all joinpoint segments. A negative AAPC indicated a decrease in the mean trend, whereas a positive AAPC indicated an increase in the mean trend. All other analyses were performed using the statistical software SAS V.9.3 (SAS Institute Inc., Cary, North Carolina, USA).

\section{RESULTS}

\section{All caesarean deliveries to nulliparous women}

This study included 155646 births to nulliparous women in Western Australia during 1996-2008. Public patients delivering in public hospitals and private patients delivering in private hospitals comprised the two largest patient groups in this population $(59 \%$ and $29 \%$, respectively). Overall, there were 45903 (29\%) caesarean sections performed during the study period. This rate increased from $20.5 \%$ in 1996 to $33 \%$ in 2008, with an average annual increase of $3.8 \%$ (95\% CI 3.0 to 4.7). Public patients in public hospitals and private patients in private hospitals were the largest two patient groups who underwent a caesarean delivery (table 1).

In figure 1, we show the overall caesarean delivery rate divided according to the four patient groups. The rate for private patients delivering in private hospitals rose from $26 \%$ in 1996 to a peak of $51 \%$ in 2005 , after which it declined to $45 \%$ in 2008. For public patients in public hospitals, the rate was $18 \%$ in 1996 with a peak of $28 \%$ in 2005 , but it remained stable after that until 2008. We calculated the average annual increase in the overall caesarean delivery rate for all patient groups until the peak in 2005. The annual rate was similar for both groups of public patients as well as private patients in public hospitals, ranging from $3.8 \%$ to $4.3 \%$ on average. On the other hand, the caesarean delivery rate for private patients in private hospitals increased by $6.5 \%$ (95\% CI $5.9 \%$ to $7.2 \%$ ) on average annually until 2005 . This increase was

Table 1 Caesarean deliveries during 1996-2008 for nulliparous women in Western Australia

\begin{tabular}{ll}
\hline & $\begin{array}{l}\text { Caesarean deliveries } \\
\text { N (\%) }\end{array}$ \\
\hline All caesarean deliveries & 45903 \\
Public patient/public hospital & $21884(48)$ \\
Public patient/private hospital & $2740(6)$ \\
Private patient/public hospital & $2311(5)$ \\
Private patient/private hospital & $18968(41)$ \\
In labour caesarean deliveries & 24803 \\
Public patient/public hospital & $13784(56)$ \\
Public patient/private hospital & $1636(7)$ \\
Private patient/public hospital & $1200(5)$ \\
Private patient/private hospital & $8183(33)$ \\
Prelabour caesarean deliveries & 21100 \\
Public patient/public hospital & $8100(38)$ \\
Public patient/private hospital & $1104(5)$ \\
Private patient/public hospital & $1111(5)$ \\
Private patient/private hospital & $10785(51)$ \\
\hline
\end{tabular}

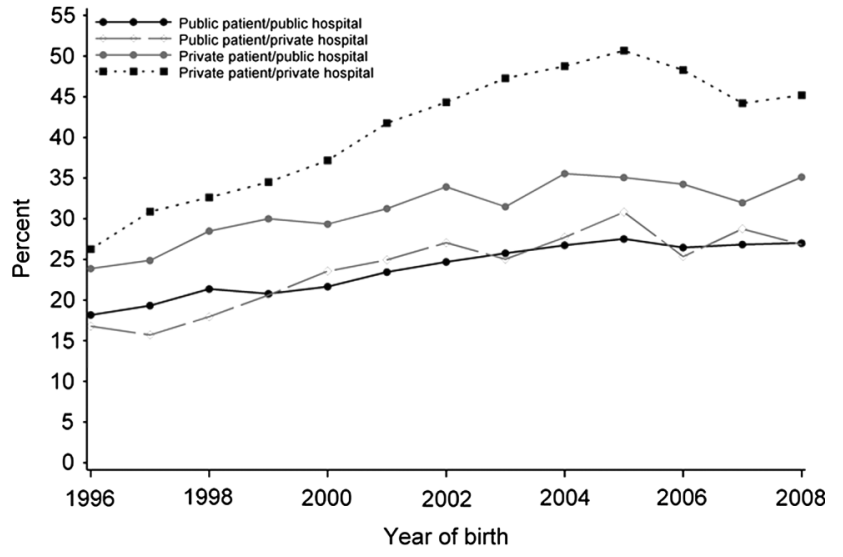

Figure 1 Percentage of caesarean deliveries for primiparous mothers in the public and private sectors in Western Australia during 1989-2008.

significantly different from the $4.3 \%$ increase for public patients in public hospitals $(\mathrm{p}<0.0001)$.

\section{In-labour and prelabour caesarean deliveries}

The caesarean deliveries were divided into two groups, those performed after labour had started (in-labour caesarean deliveries) and those performed prior to the onset of labour (prelabour caesarean deliveries). In-labour and prelabour deliveries comprised $54 \%$ and $46 \%$ of all caesarean deliveries, with public patients in public hospitals being the largest patient group (56\%) of all in-labour deliveries and private patients in private hospitals being the largest patient group (51\%) of all prelabour deliveries (table 1).

The rates for in-labour and prelabour caesarean deliveries divided according to the four patient groups are shown in figures 2 and 3. The in-labour rate increased similarly for all four patient groups, from around $11-14 \%$ in 1996 to around $17-19 \%$ in 2008 (figure 2). For prelabour caesarean deliveries, the average annual rate change for public patients delivering in public

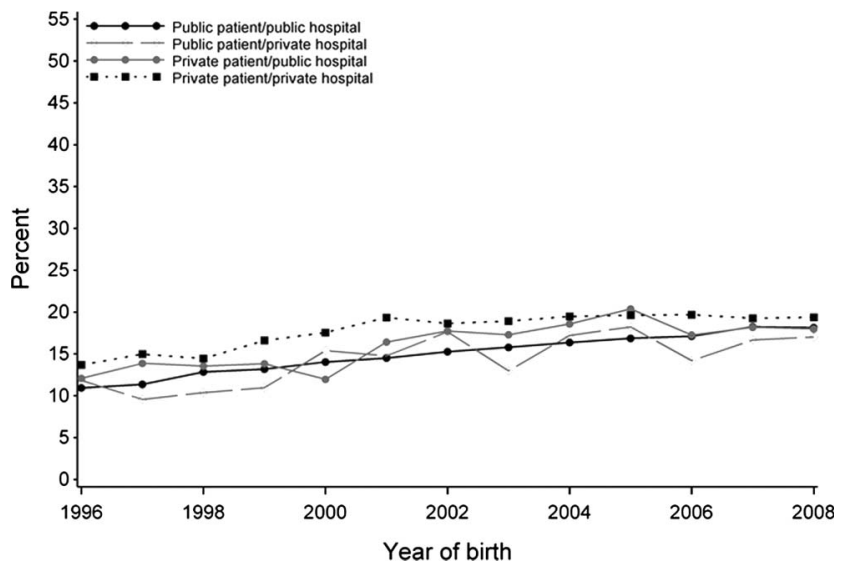

Figure 2 Percentage of caesarean deliveries in labour for nulliparous women in the public and private sectors in Western Australia during 1989-2008. 


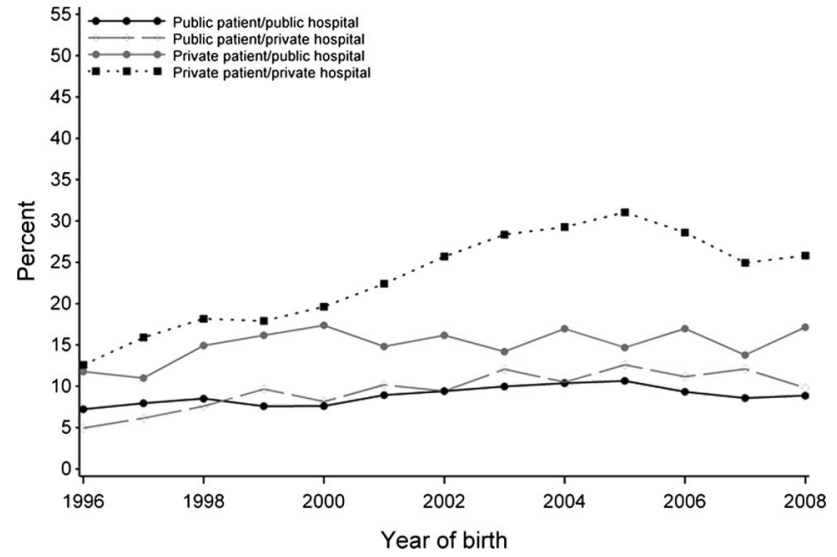

Figure 3 Percentage of prelabour caesarean deliveries for nulliparous women in the public and private sectors in Western Australia during 1989-2008.

hospitals was relatively stable over the time period examined $(1.2 \%, 95 \% \mathrm{CI}-1.1 \%$ to $3.5 \%)$, with the rate starting at 7\% in 1996 and ending at 9\% in 2008 (figure 3). Public patients in private hospitals and private patients in public hospitals had similar average annual prelabour rate changes to public patients in public hospitals during the study period. However, the rate of prelabour caesarean deliveries for private patients delivering in private hospitals increased from $13 \%$ in 1996 to $26 \%$ in 2008 (figure 3). The average annual rise of the prelabour rate until 2008 for this patient group (5.2\%, 95\% CI $3.7 \%$ to $6.8 \%$ ) was four times the rise for public patients delivering in public hospitals $(\mathrm{p}=0.005)$.

To explore possible reasons for the significant increase in the rate of prelabour caesarean delivery for private patients in private hospitals, we examined the trend in the proportion of breech presentation, placenta praevia or multiple pregnancies during the study period for the four patient groups. The proportion of breech presentations increased by $1.2 \%$ (95\% CI $0.3 \%$ to $2.1 \%$ ) on average annually for private patients in private hospitals, but decreased for public patients in public hospitals $(-1.6 \%, 95 \%$ CI $-3.1 \%$ to $-0.1 \%)$. The mean annual proportion of placenta praevia for public patients in public hospitals decreased by $5.4 \%$ (95\% CI $-7.8 \%$ to $-2.9 \%$ ), but increased by $7.1 \%$ (95\% CI $4.0 \%$ to $10.3 \%$ ) for private patients in private hospitals. The proportion of multiple pregnancies remained stable for both public patients in public hospitals $(0.1 \%, 95 \%$ CI $-2.3 \%$ to $2.7 \%)$ and private patients in private hospitals $(-1.8 \%$, $95 \%-4.1 \%$ to $0.7 \%$ ) during the study period.

Given the rise in placenta praevia and breech deliveries for private patients during the study period, the next step was to remove all breech deliveries and pregnancies complicated by placenta praevia from the data before reanalysing the prelabour caesarean delivery rate (figure 4). This was done to assess whether the rise in placenta praevia and breech deliveries in private patients delivering in private hospitals accounted for some or all

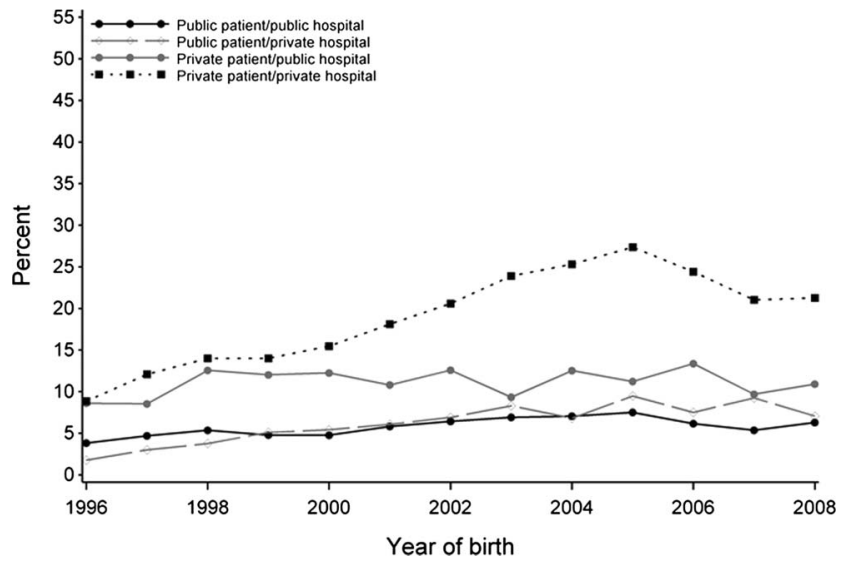

Figure 4 Percentage of prelabour caesarean deliveries for nulliparous women in the public and private sectors in Western Australia during 1989-2008 where all breech deliveries and placenta praevia have been removed.

of the rate increase of prelabour caesarean deliveries for this patient group. After the exclusion, 145347 births remained, including 14601 prelabour caesarean deliveries where $34 \%$ were in public patients delivering in public hospitals and $56 \%$ in private patients delivering in private hospitals. For this restricted population, the rate of prelabour caesarean deliveries for private patients in private hospitals started at 9\% in 1996 with a peak of $27 \%$ in 2005 before dropping to $20 \%$ in 2008 . For public patients in public hospitals, the rate was $3.8 \%$ in 1996 and peaked at $7.5 \%$ in 2005 before going down to $6.3 \%$ in 2008 (figure 4). The difference in the average annual rate increase between the two groups from 1996 and until the peak in 2005 was statistically significant $(p=0.0007)$ and all trend lines had a similar shape to those shown in figure 3 , which included the full set of data.

\section{DISCUSSION}

In this study, we investigated the involvement of the public and private sectors in the rising caesarean section rate in Australia during 1996-2008. The results indicated that the rate of caesarean deliveries has increased most rapidly on average for women delivering as private patients in private hospitals. This increase could mostly be attributed to an increase in prelabour caesarean deliveries for this group of women. The increasing prelabour caesarean delivery rate in nulliparous women delivering as private patients in private hospitals in Western Australia could not be explained by the increasing proportions of breech presentations, placenta praevia or multiple pregnancies.

This retrospective study used administrative hospital data collected at the time of birth for the entire population of Western Australia. Using this data therefore minimised limitations due to sample size, selection bias or retrospective ascertainment of outcome measures. However, as administrative data collections tend to only gather information that are clinically relevant or 
important for administrative purposes, we were restricted in the detail of information available to us. For example, we did not have specific information on indications for caesarean section. Such information would have been useful to more accurately determine the reasons for the rise in privately performed prelabour caesarean sections that we found in this study.

Recent evidence has been conflicting regarding whether the private sector in Australia contributes significantly to the increasing caesarean section rate. ${ }^{33} 34$ Roberts $e t a l^{34}$ investigated the rise in caesarean delivery rates for nulliparous women in New South Wales, Australia by funding source only and found that the rise from 1994 to 2009 was similar between women giving birth as private or public patients. Our findings appear to contradict this, particularly as when we grouped our data by funding source only, we found a significant difference in the average annual caesarean delivery rate increase between private and public patients until the peak in $2005(p<0.0001)$. However, when we investigated the whole study period from 1996 to 2008, we found no difference between the two patient groups $(p=0.3)$, which is in accordance with the results from Roberts $e t$ al.

Dahlen $e t a l^{33}$ also used data from New South Wales, but investigated hospital type only and found that the increase in the caesarean delivery rate from 1996/1997 to $2000 / 2008$ was higher in private hospitals $(11 \%)$ than public hospitals (7\%) for women at low risk. The authors did not perform a separate analysis of the overall caesarean rate for primiparas and multiparas, and therefore it cannot be discerned whether this difference is due to the primary or repeat caesarean delivery rate. In this study, we investigated nulliparous women only and found that an increase in the prelabour caesarean delivery rate has been driving the caesarean delivery rate increase for private patients in private hospitals. This appears to corroborate results from Dahlen et $a l^{33}$ for primiparas at low risk, indicating that caesarean delivery rates in private hospitals have risen at twice the rate for prelabour caesarean deliveries $(4.1-8.9 \%)$ than in-labour caesarean deliveries (12.3-18.2\%).

Specific reasons for the large difference in caesarean section rates between the private and public sectors in Australia are largely unknown, but differences in maternity service provision and variation in obstetric practice are likely to play a role. A study from a large teaching hospital in the UK reported a significant increase in maternal request $(0.6-19.5 \%)$ and breech delivery $(9-24 \%)$ as indications for caesarean section from 1976 to 1996, but found no difference in fetal distress $(17-18 \%)$ as an indication. ${ }^{37}$ Also, research from Scotland found a rise in the caesarean section rate in a large teaching hospital from 1962 to 1992 despite no change in the failure to progress in labour or fetal indications. ${ }^{38}$ The authors suggested that the rise in the caesarean section rate was due to a lowering threshold concerning the decision to carry out a caesarean section rather than changes in obstetric management. ${ }^{38}$
Furthermore, a recent randomised controlled trial in a large Australian teaching hospital found a 22\% reduction in the caesarean section rate under continuity of midwifery care compared with standard care with no difference in perinatal mortality. ${ }^{39}$ This suggests that even though caesarean section rates decrease, there was little evidence to suggest that perinatal mortality increased, indicating that increasing fetal risk does not appear to be a major contributor to the increasing caesarean section rates.

Other factors that have been mentioned as significant contributors to the rising caesarean section rate are maternal and clinician preferences. For example, privately insured women who are well educated, confident and with mature personalities have been found to be at higher risk of obstetric interventions than other women. ${ }^{40}$ This is likely to be due to many contributing factors; however, it is possible that fee-paying mothers have greater expectations for their own hospital care and the care of their infant than other mothers. ${ }^{41}$ Also, some evidence indicates that the likelihood of an obstetrician responding positively to a maternal request for a caesarean section depends more on cultural factors, legal liability and how the request is framed rather than medical evidence. ${ }^{42}$ Evidence from Brazil suggests that the high rates of caesarean section in the private sector are, however, not a reflection of women's preferences, ${ }^{43}$ and the authors suggest that obstetricians may see advantages in prelabour caesarean section such as better control of the birth process and timing of delivery. ${ }^{44}$

Given the high rate of prelabour caesarean deliveries in the private sector, ${ }^{33}$ the rising caesarean section rate in Australia is also likely to have been influenced by the increasing number of private hospitals, governmental private health insurance incentive policy reforms and increase in the numbers of women with private health insurance. ${ }^{45}$ For example, there was a $16 \%$ increase in the number of private hospitals in Australia during 1990-2000, whereas public hospital numbers increased by only $3 \%$ over the same period. ${ }^{46}$ Also, the federal government announced policy reforms in 2000 which increased the percentage of the Australian population with private health insurance from $30 \%$ in 1999 to $\sim 45 \%$ in $2001 .{ }^{47}$ Our previous findings have shown that, following this policy introduction and the resulting increase in private health insurance membership, the rate of prelabour caesarean sections in Western Australia increased by $10 \% .^{45}$

In summary, our results indicate that an increase in the prelabour caesarean delivery rate has driven the caesarean delivery rate increase for nulliparous private patients in private hospitals in Western Australia since 1999. The increase could not be explained by an increase in breech deliveries, multiples or pregnancies complicated by placenta praevia. These results indicate that differences in delivery management and obstetric practice are likely to play a role in the rising caesarean section rate. Future research with more detailed 
information on indications for prelabour caesarean section is needed to understand the underlying reasons for these findings.

\section{Author affiliations}

${ }^{1}$ Telethon Institute for Child Health Research, Centre for Child Health Research, University of Western Australia, Subiaco, Western Australia, Australia

${ }^{2}$ Centre for Health Services Research, School of Population Health, The University of Western Australia, Perth, Western Australia, Australia ${ }^{3}$ Department of Epidemiology and Public Health, Yale Center for Perinatal, Pediatric, and Environmental Epidemiology, School of Medicine, Yale University, New Haven, Connecticut, USA

${ }^{4}$ School of Women's and Infant's Health, University of Western Australia, King Edward Memorial Hospital, Perth, Western Australia, Australia

Acknowledgements We thank the Data Linkage Branch of the Western Australian Department of Health for provision of the data.

Contributors KE initiated the research, designed the study, analysed and interpreted the data and wrote the article. She will act as the guarantor for the paper. SS gave clinical advice and contributed to the writing of the paper. FAH and GP gave advice on the statistical methods used for analysis, discussed ideas and contributed to the paper. NdeK, HL and FJS supervised the work, gave advice and contributed to the paper. All authors had full access to all of the data in the study and can take responsibility for the integrity of the data and the accuracy of the data analysis.

Funding The research was funded by the Australia's National Health and Medical Research Council (grants 634533 and 573122). The funder had no involvement in the analysis or the writing of the manuscript.

Competing interests None.

Ethics approval The use of deidentified, administrative health data for this study without patient consent was approved by the Human Research Ethics Committee of the WA Department of Health. This study was performed in accordance with the Declaration of Helsinki.

Provenance and peer review Not commissioned; externally peer reviewed.

Data sharing statement The Western Australian Department of Health does not allow any of its data to be shared with the public.

\section{REFERENCES}

1. Menacker F, Hamilton BE. Recent trends in cesarean delivery in the United States. National Center for Health Statistics Data Brief No. 35. U.S. Department of Health and Human Services, Centers for Disease Control and Prevention, 2010.

2. Liu S, Rusen ID, Joseph KS, et al. Recent trends in caesarean delivery rates and indications for caesarean delivery in Canada. J Obstet Gynaecol Can 2004;26:735-42.

3. Giving birth in Canada: regional trends from 2001-2002 to 20052006. Canadian Institute for Health Information. 2007. http://www. cihi.ca (accessed 25 Mar 2013).

4. Lancaster P, Huang J, Pedisich E. Australia's mothers and their babies 1991. Perinatal Statistics Series no. 1. Cat. no. AlHW 240. Australian Institute of Health and Welfare, National Perinatal Statistics Unit, Sydney, 1994.

5. Laws PJ, Li Z, Sullivan EA. Australia's mothers and babies 2008. Perinatal Statistics Series no. 24. Canberra, 2010.

6. Statistical Bulletin: NHS Maternity Statistics, England: 2011-2012, 2012.

7. Chigbu CO, lloabachie GC. The burden of caesarean section refusal in a developing country setting. BJOG 2007;114:1261-5.

8. Paxton A, Maine D, Freedman L, et al. The evidence for emergency obstetric care. Int J Gynaecol Obstet 2005;88:181-93.

9. Allen VM, O'Connell CM, Liston RM, et al. Maternal morbidity associated with cesarean delivery without labor compared with spontaneous onset of labor at term. Obstet Gynecol 2003;102:477-82

10. Betran AP, Merialdi M, Lauer JA, et al. Rates of caesarean section: analysis of global, regional and national estimates. Paediatr Perinat Epidemiol 2007;21:98-113.
11. Bodner K, Wierrani F, Grunberger W, et al. Influence of the mode of delivery on maternal and neonatal outcomes: a comparison between elective cesarean section and planned vaginal delivery in a low-risk obstetric population. Arch Gynecol Obstet 2011;283:1193-8.

12. Geller EJ, Wu JM, Jannelli ML, et al. Neonatal outcomes associated with planned vaginal versus planned primary cesarean delivery. J Perinatol 2010;30:258-64.

13. Harper LM, Odibo AO. Mode of delivery and obstetric outcomes in Asia. Womens Health (Lond Engl) 2010;6:365-6.

14. Knight M, Kurinczuk JJ, Spark $P$, et al. Cesarean delivery and peripartum hysterectomy. Obstet Gynecol 2008;111:97-105.

15. Kolas T, Saugstad OD, Daltveit AK, et al. Planned cesarean versus planned vaginal delivery at term: comparison of newborn infant outcomes. Am J Obstet Gynecol 2006;195:1538-43.

16. Liston FA, Allen VM, O'Connell CM, et al. Neonatal outcomes with caesarean delivery at term. Arch Dis Child Fetal Neonatal Ed 2008;93:F176-82.

17. Moore $\mathrm{HC}$, de Klerk $\mathrm{N}$, Holt $\mathrm{P}$, et al. Hospitalisation for bronchiolitis in infants is more common after elective caesarean delivery. Arch Dis Child 2012:97:410-4.

18. Silver RM, Landon MB, Rouse DJ, et al. Maternal morbidity associated with multiple repeat cesarean deliveries. Obstet Gynecol 2006;107:1226-32.

19. Fogelson NS, Menard MK, Hulsey T, et al. Neonatal impact of elective repeat cesarean delivery at term: a comment on patient choice cesarean delivery. Am J Obstet Gynecol 2005;192:1433-6.

20. Levine EM, Ghai V, Barton JJ, et al. Mode of delivery and risk of respiratory diseases in newborns. Obstet Gynecol 2001;97:439-42.

21. Souza JP, Gulmezoglu A, Lumbiganon P, et al. Caesarean section without medical indications is associated with an increased risk of adverse short-term maternal outcomes: the 2004-2008 WHO Global Survey on Maternal and Perinatal Health. BMC Med 2010;8:71.

22. Tracy SK, Tracy MB, Sullivan E. Admission of term infants to neonatal intensive care: a population-based study. Birth 2007;34:301-7.

23. Zwecker P, Azoulay L, Abenhaim HA. Effect of fear of litigation on obstetric care: a nationwide analysis on obstetric practice. $A m \mathrm{~J}$ Perinatol 2011;28:277-84.

24. Robson SJ, Tan WS, Adeyemi A, et al. Estimating the rate of cesarean section by maternal request: anonymous survey of obstetricians in Australia. Birth 2009;36:208-12.

25. Penn Z, Ghaem-Maghami S. Indications for caesarean section. Best Pract Res Clin Obstet Gynaecol 2001;15:1-15.

26. MacDorman MF, Menacker F, Declercq E. Cesarean birth in the United States: epidemiology, trends, and outcomes. Clin Perinatol 2008;35:293-307, v.

27. Howell S, Johnston T, Macleod SL. Trends and determinants of caesarean sections births in Queensland, 1997-2006. Aust N Z J Obstet Gynaecol 2009;49:606-11.

28. O'Leary CM, de Klerk N, Keogh J, et al. Trends in mode of delivery during 1984-2003: can they be explained by pregnancy and delivery complications? BJOG 2007;114:855-64.

29. Stavrou EP, Ford JB, Shand AW, et al. Epidemiology and trends for Caesarean section births in New South Wales, Australia: a population-based study. BMC Pregnancy Childbirth 2011;11:8.

30. Barber EL, Lundsberg LS, Belanger K, et al. Indications contributing to the increasing cesarean delivery rate. Obstet Gynecol 2011;118:29-38.

31. Foster M, Fleming J. The health care system in Australia. Health care practice in Australia. Melbourne, Australia: Oxford University Press, 2008:46-73.

32. Harris MG, Harris RD. The Australian health system: continuity and change. J Health Hum Serv Adm 1998;20:442-67.

33. Dahlen HG, Tracy S, Tracy M, et al. Rates of obstetric intervention among low-risk women giving birth in private and public hospitals in NSW: a population-based descriptive study. BMJ Open 2012;2: e001723.

34. Roberts CL, Algert CS, Ford JB, et al. Pathways to a rising caesarean section rate: a population-based cohort study. BMJ Open 2012;2:e001725.

35. Holman CD, Bass AJ, Rouse IL, et al. Population-based linkage of health records in Western Australia: development of a health services research linked database. Aust N Z J Public Health 1999;23:453-9.

36. Private care for public patients: the Joondalup Health Campus: Auditor General, Western Australia, 1997.

37. MacKenzie IZ, Cooke I, Annan B. Indications for caesarean section in a consultant obstetric unit over three decades. J Obstet Gynaecol 2003;23:233-8.

38. Leitch CR, Walker JJ. The rise in caesarean section rate: the same indications but a lower threshold. Br J Obstet Gynaecol 1998;105:621-6. 
39. McLachlan H, Forster D, Davey M, et al. Effects of continuity of care by a primary midwife (caseload midwifery) on caesarean section rates in women of low obstetric risk: the COSMOS randomised controlled trial. BJOG 2012;119:1483-92.

40. Fisher J, Smith A, Astbury J. Private health insurance and a healthy personality: new risk factors for obstetric intervention? J Psychosom Obstet Gynaecol 1995;16:1-9.

41. Roberts CL, Tracy S, Peat B. Rates for obstetric intervention among private and public patients in Australia: population based descriptive study. BMJ 2000;321:137-41.

42. Habiba M, Kaminski M, Da Fre M, et al. Caesarean section on request: a comparison of obstetricians' attitudes in eight European countries. BJOG 2006;113:647-56.
43. Potter JE, Berquo E, Perpetuo IH, et al. Unwanted caesarean sections among public and private patients in Brazil: prospective study. BMJ 2001;323:1155-8.

44. Hopkins K. Are Brazilian women really choosing to deliver by cesarean? Soc Sci Med 2000;51:725-40.

45. Einarsdottir K, Kemp A, Haggar FA, et al. Increase in caesarean deliveries after the Australian private health insurance incentive policy reforms. PLOS ONE 2012;7:e41436.

46. Australian hospital statistics 2000-01. Health services series no. 19. Canberra: Australian Institute of Health and Welfare, 2002.

47. Cormack M. Private health insurance: the problem child faces adulthood. Aust Health Rev 2002;25:38-51. 